\title{
Surgical Anatomy of the Veins of the Lower Limb
}

\author{
GÉZA MÓZES, M.D., Ph.D., STEPHEN W. CARMICHAEL, Ph.D., D.Sc., and \\ PETER GLOVICZKI, M.D.
}

\begin{abstract}
With the advent of new surgical techniques, such as subfascial endoscopic perforator surgery, venous anatomy of the lower limb gained distinguished attention. Here, based on our surgical experience and observations on several dissections, we describe the embryology and the gross anatomy of the superficial, deep, and perforating veins. The lesser and greater saphenous veins, their named tributaries, such as the posterior arch vein, and numerous unnamed small veins form the superficial venous system. Perforating veins drain the superficial into the deep veins. Incompetent superficial, deep and perforating veins may contribute to chronic venous insufficiency. Clinically the most important perforating veins are located in the medial aspect of the leg at just behind the ankle, at 7 to 9 and 10 to $12 \mathrm{~cm}$ from the ankle (Cockett I-III) or they are paratibial at 18 to $22 \mathrm{~cm}$ proximal from the ankle (“24"-cm perforator). Deep, axial veins, frequently paired, in the lower limb follow their corresponding arteries.
\end{abstract}

Keywords Anatomy, embryology, leg veins

\section{EMBRYOLOGY}

The early limb bud is supplied by a fine capillary network that originates from an axial artery of the lower limb. ${ }^{1}$ This axial artery develops into the internal iliac artery, the inferior gluteal artery, the artery to the sciatic nerve, the popliteal artery, and the peroneal artery. Later, the femoral artery develops

G.M., Resident, Department of Surgery; S.W.C., Professor and Chair, Department of Anatomy; P.G., Professor of Surgery, Chair, Division of Vascular Surgery, Mayo Clinic, Rochester, MN.

Copyright (C) 2000 by Thieme Medical Publishers, Inc., 333 Seventh Avenue, New York, NY 10001, USA. Tel. +l(212) 584-4662. 0894-8046,p; 2000,12,2,107,116,ftx,en;pvs00071 
from the external iliac artery and grows inferiorly to join the popliteal artery. The blood from the axial artery travels through a capillary network and collects in a marginal sinus that extends around the apex of the limb bud, just deep to the apical ectodermal ridge. Blood returns from the limb bud through venous channels that develop along the preaxial and postaxial borders of the limb. Early on, blood drains from the marginal sinus into superficial venous plexuses, but as development continues more and more blood is shunted into deeper channels that become the deep veins. Valves form in the veins relatively early, and it is thought that the final number of valves is reached by the 6th month of fetal life.

The role of the vasculature directing the development of the limb is not clear. Some embryologists claim that the vessels play an important role in organizing the muscles, bones, and other structures during development, whereas others claim that the vessels develop after the onset of cartilage and muscle differentiation, indicating a minor role for vessels in directing limb formation. More investigation into limb development is necessary before the role of the vasculature is clarified, but it is likely that blood vessels will be found to be prime movers in some aspects of development and secondary responders in other aspects.

\section{ANATOMY}

Venous drainage of the lower limb is maintained by the superficial and deep veins that are connected to each other by the perforating veins. Unidirectional flow is secured by valves in each system.

\section{Superficial Veins}

The dorsal metatarsal veins collect blood from the digital veins of the foot and empty into the dorsal venous arch, which continues into the lesser and greater saphenous veins on the lateral and medial sides of the foot, respectively (Fig. 1). * The lesser saphenous vein, accompanied by the sural nerve, ascends on the posterolateral aspect of the leg and usually joins the popliteal vein in the proximal popliteal fossa (Fig. 2). ${ }^{3}$ The greater saphenous vein, accompanied by the saphenous nerve, ascends anterior to the medial malleolus, crosses the tibia, and runs medial to the knee to continue anterior in the thigh (Fig. 3). ${ }^{4}$ It receives the posterior arch pein (Leonardo's vein) below the knee. ${ }^{5,6}$ The posterior arch vein drains a venous network around the medial malleolus and runs on the posteromedial aspect of the leg. The lateral and/or medial accessory saphenous veins, the superficial circumflex iliac, the superficial epi-

*The current Terminologia Anatomica ${ }^{2}$ suggests terms, that are somewhat different from those used in the surgical practice. In this text we follow the surgical terminology, and anatomic terms are listed here in parenthesis: peroneal vein (fibular vein), lesser and greater saphenous veins (small and great saphenous veins), common and superficial femoral vein (femoral vein). 


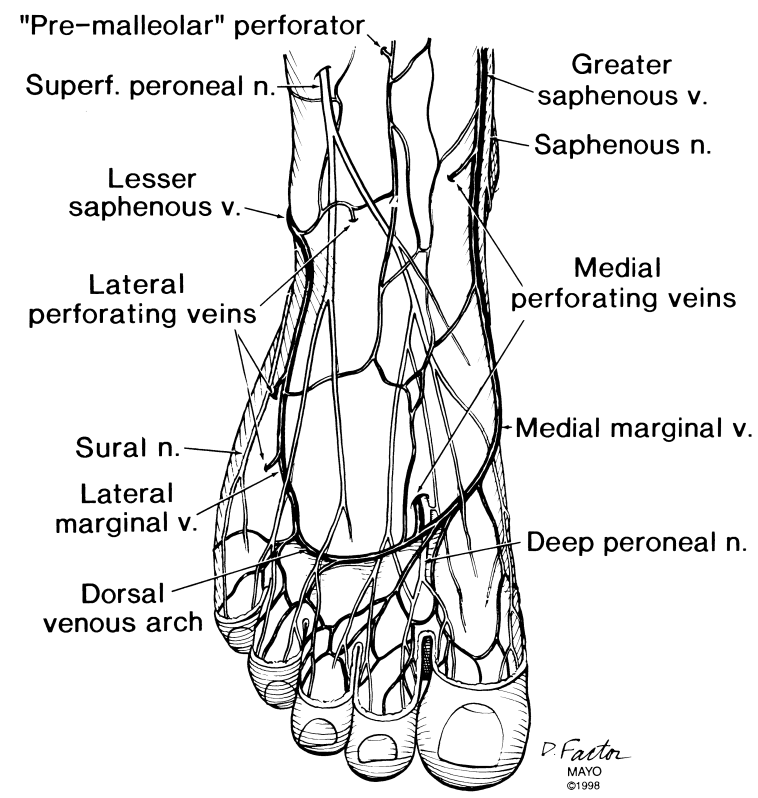

Fig. 1 Anatomy of the superficial and perforating veins of the foot. (With permission of the Mayo Clinic and Foundation.)

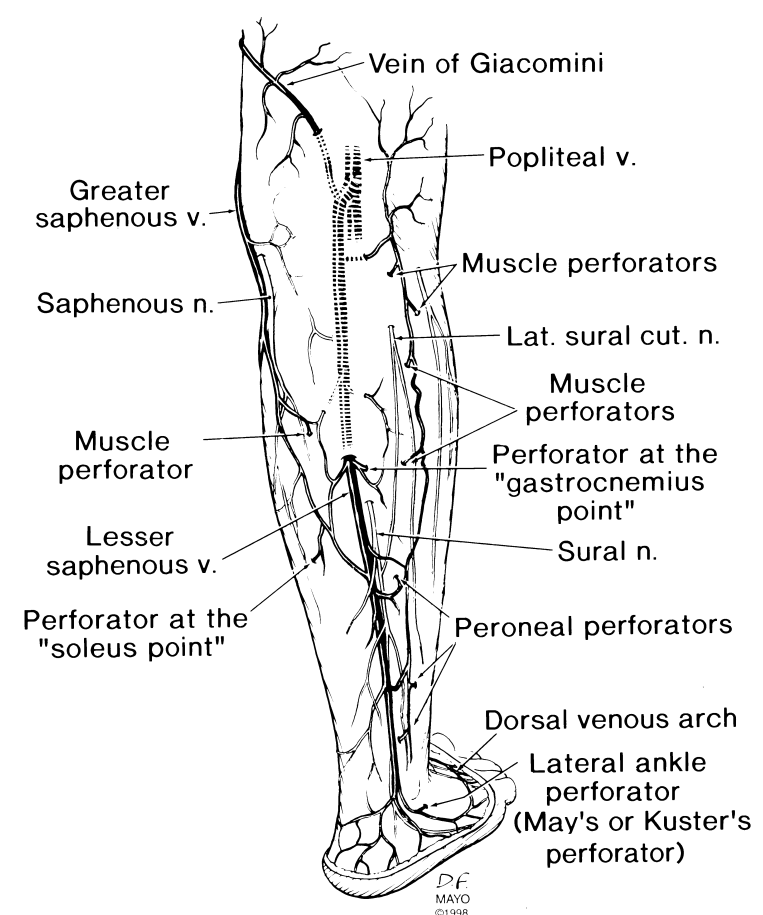

Fig. 2 Anatomy of the posterolateral superficial and perforating veins of the leg. (With permission of the Mayo Clinic and Foundation.) 


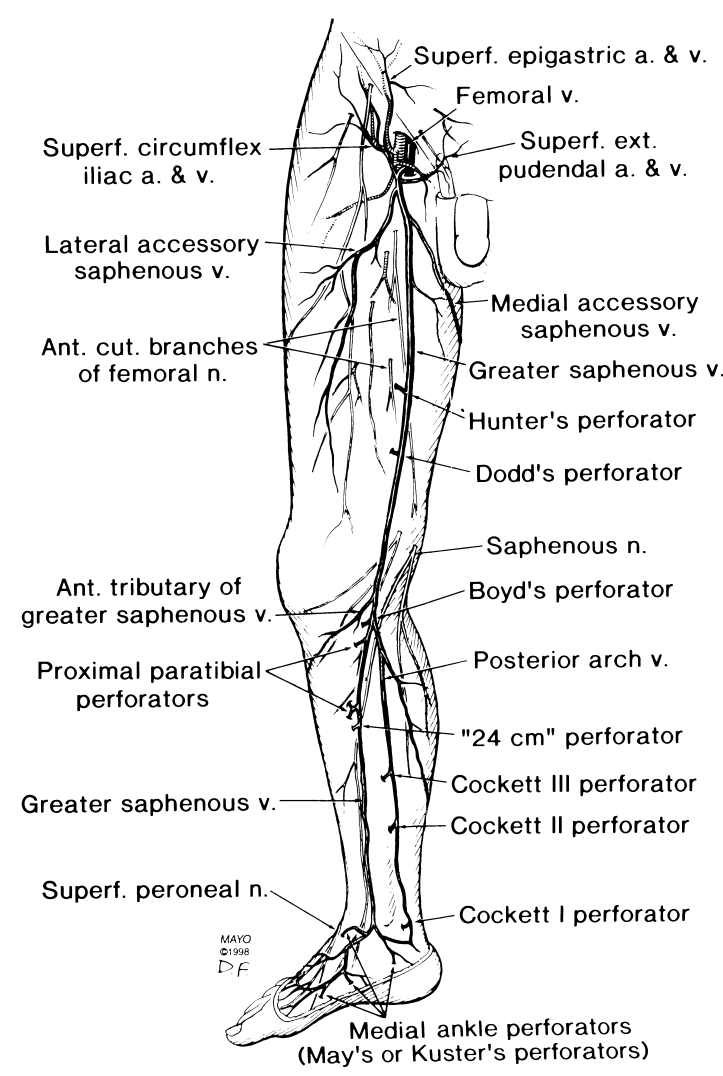

Fig. 3 Anatomy of medial superficial and perforating veins of the leg. (With permission of the Mayo Clinic and Foundation.)

gastric, and the superficial external pudendal veins all drain into the greater saphenous vein immediately before it empties into the femoral vein two finger breadths below the inguinal ligament. ${ }^{7,8}$ The vein of Giacomini is a superficial vein in the lower posterior thigh connecting between the two saphenous systems (communicating vein).

\section{Deep Veins}

Deep veins accompany the arteries and their branches (Fig. 4). ${ }^{4}$ Many of the deep veins exist as a pair of veins (venae comitantes) that are closely applied to the artery of the same name. It is thought that this close anatomic vascular arrangement allows for a countercurrent heat exchange mechanism; as arterial blood proceeds down the limb, it may be cooled down by venous blood, which in turn is being warmed up before it returns to the pelvis. In this fashion, heat 


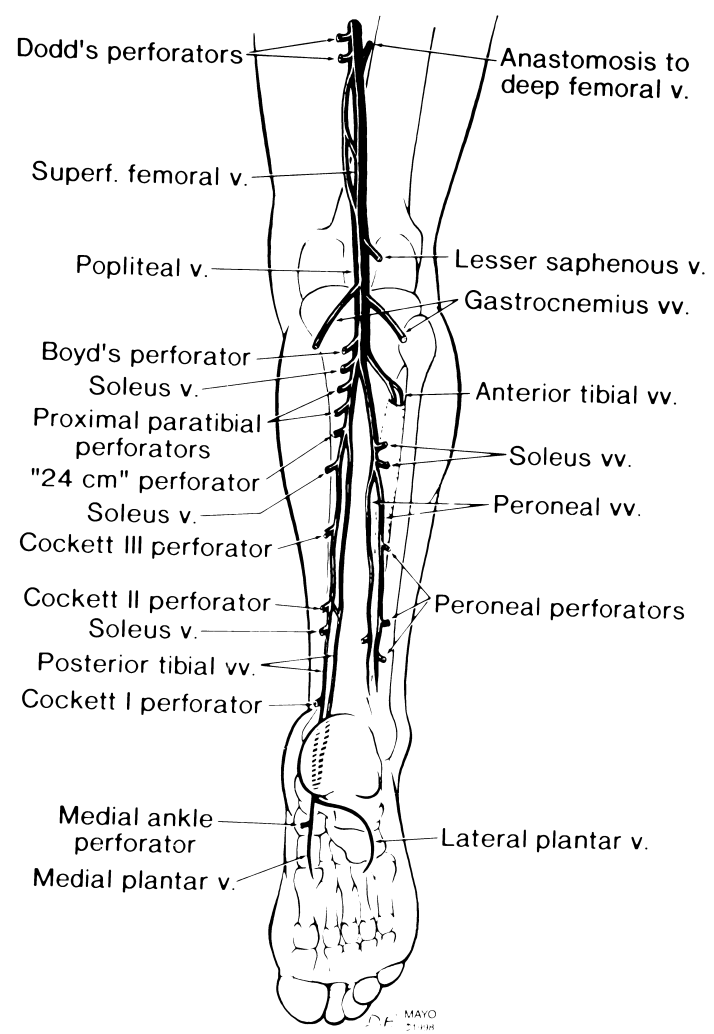

Fig. 4 Anatomy of the deep veins of the lower limb, posterior view. (With permission of the Mayo Clinic and Foundation.)

may be conserved in a cold environment. Furthermore, the distal parts of the limb may become cold, even freeze, but the organism can survive.

The deep venous system originates as the dorsalis pedis veins, which continue into the paired anterior tibial veins at the ankle. The four plantar metatarsal veins drain the plantar digital veins into the deep plantar venous arch, which continues in the medial and lateral plantar veins and finally empties into the paired posterior tibial veins. In the calf, the posterior tibial veins run between the edges of the flexor digitorum longus and tibialis posterior muscles, under the fascia of the deep posterior compartment. The posterior tibial veins join with the paired peroneal and the anterior tibial veins, and these continue proximally as the popliteal pein. Venous sinuses of the soleus muscle are drained by the soleal veins into the posterior tibial and peroneal veins. Bilateral gastrocnemius veins drain usually directly into the popliteal vein, distal to the confluence of the lesser saphenous vein with the popliteal vein. The popliteal vein continues into the superficial and later common 
femoral veins, which continues as the external iliac vein when it passes under the inguinal ligament (note: the superficial femoral vein is a deep vein). The profunda femoris and the greater saphenous veins are the main tributaries of the common femoral vein.

\section{Perforating Veins}

Perforating veins connect the superficial to the deep veins as they pierce the deep fascia. ${ }^{9-11}$ In the foot, perforating veins are either valveless or valves are oriented to allow flow into the superficial veins. ${ }^{12}$ In the leg and thigh the perforating veins usually have one to three bicuspid valves to direct blood from the superficial to the deep veins. The smallest $(<1 \mathrm{~mm})$ perforating veins are valveless.

Direct perforating veins connect superficial to deep, axial veins, whereas indirect perforators connect superficial veins to muscle veins and muscular venous sinuses. ${ }^{13}$ Indirect perforators are irregularly distributed, whereas the direct ones show constant anatomic distribution. There are five clinically important groups of direct perforating veins, those of the foot, of the medial, posterolateral and anterior calf, and of the thigh. ${ }^{14-20}$

In the foot there is a large perforator in the first interosseous space that connects the superficial, dorsal venous arch with the dorsalis pedis veins (Fig. 1). In the ankle and foot the lesser and greater saphenous veins have numerous connections to the dorsalis pedis and to the lateral and medial plantar veins, respectively. Ankle perforators are named after Kuster and May.

In the medial calf there is an average of seven to eight direct perforators clustered in four groups in the distal half of the leg (Fig. 3, Table 1). The Cockett I is the lowest perforator, located just behind the medial ankle. Cockett II and III perforators are in a distance within 2 to $4 \mathrm{~cm}$ from the medial edge of the tibia at 7 to 9 and 10 to $12 \mathrm{~cm}$ proximal from the tip of the medial malleolus, respectively. ${ }^{20}$ The Cockett perforators connect the posterior arch vein or other tributaries of the greater saphenous vein with the posterior tibial veins. In the proximal medial calf direct perforating veins are paratibial and located at 18 to 22 (also called " $24-\mathrm{cm}$ perforators" after its distance from the sole), 23 to 27 , and 28 to $32 \mathrm{~cm}$ from the medial malleolus (Fig. 5).20 The majority of these paratibial veins drain tributaries of the greater saphenous vein. One of the paratibial perforators, named after Boyd, is located right distal to the knee. ${ }^{21}$

Several direct medial calf perforators run across the superficial posterior compartment before entering the deep posterior compartment and draining into the deep veins as the superficial posterior compartment covers almost the all deep posterior compartment except of its very distal part (Fig. 6, p. 114, Fig. 7, p. 115). Perforators, therefore, are easily accessible during subfascial endoscopic perforator surgery as ports are introduced into the superficial posterior compartment. ${ }^{22-24}$ To gain access to other direct, medial calf perforators 
Table 1 Studies on the Location of Direct Medial Perforating Veins in the Leg

\begin{tabular}{|c|c|c|c|c|c|}
\hline \multirow[b]{2}{*}{$\begin{array}{l}\text { 1st Author } \\
\text { (Year) }\end{array}$} & \multicolumn{2}{|c|}{ Number of Legs } & \multicolumn{3}{|c|}{ Location of Medial Perforating Veins* } \\
\hline & $\begin{array}{l}\text { Anatomic } \\
\text { Dissections }\end{array}$ & $\begin{array}{l}\text { Surgical } \\
\text { Findings }\end{array}$ & Cockett II & Cockett III & $\begin{array}{l}\text { Proximal } \\
\text { Paratibial PVs }\end{array}$ \\
\hline $\begin{array}{l}\text { Linton } \\
\quad(1938)\end{array}$ & 10 & 50 & $\begin{array}{l}\text { Distal third } \\
\text { of the leg }\end{array}$ & $\begin{array}{l}\text { Middle third } \\
\text { of the leg }\end{array}$ & $\begin{array}{l}\text { Proximal third } \\
\text { of the leg }\end{array}$ \\
\hline $\begin{array}{r}\text { Sherman } \\
(1948)\end{array}$ & 92 & 901 & $13.5 \mathrm{~cm}$ & $18.5 \mathrm{~cm}$ & $\begin{array}{l}24 \mathrm{~cm}, 30 \mathrm{~cm}, 35 \\
\mathrm{~cm}, 40 \mathrm{~cm}\end{array}$ \\
\hline $\begin{array}{l}\text { Cockett } \\
(1953)\end{array}$ & 21 & 201 & $13-14 \mathrm{~cm}$ & $16-17 \mathrm{~cm}$ & At the knee \\
\hline $\begin{array}{l}\text { O'Donnell } \\
\text { (1977) }\end{array}$ & - & 39 & \multicolumn{2}{|c|}{$\begin{array}{l}\text { Half of the incompetent PVs is } \\
\text { between } 10 \text { and } 15 \mathrm{~cm}^{* *} \\
\left(15-20 \mathrm{~cm}^{*}\right)\end{array}$} & Few incompetent PVs \\
\hline Fischer & - & 194 & \multicolumn{3}{|c|}{ Random distribution of incompetent PVs } \\
\hline $\begin{array}{l}\text { Mózes } \\
(1996)\end{array}$ & 40 & - & $\begin{array}{l}7-9 \mathrm{~cm}^{* *} \\
\left(12-14 \mathrm{~cm}^{*}\right)\end{array}$ & $\begin{array}{l}10-12 \mathrm{~cm}^{* *} \\
\left(15-17 \mathrm{~cm}^{*}\right)\end{array}$ & $\begin{array}{r}18-22 \mathrm{~cm}^{* *}, 23-27 \\
\mathrm{~cm}^{* *}, 28-32 \mathrm{~cm}^{* *} \\
\left(23-27 \mathrm{~cm}^{*}\right),(28-32 \\
\left.\mathrm{cm}^{*}\right),\left(33-37 \mathrm{~cm}^{*}\right)\end{array}$ \\
\hline
\end{tabular}

* Distances measured from the sole.

${ }^{* *}$ Distances measured from the lower tip of the medial malleolus.

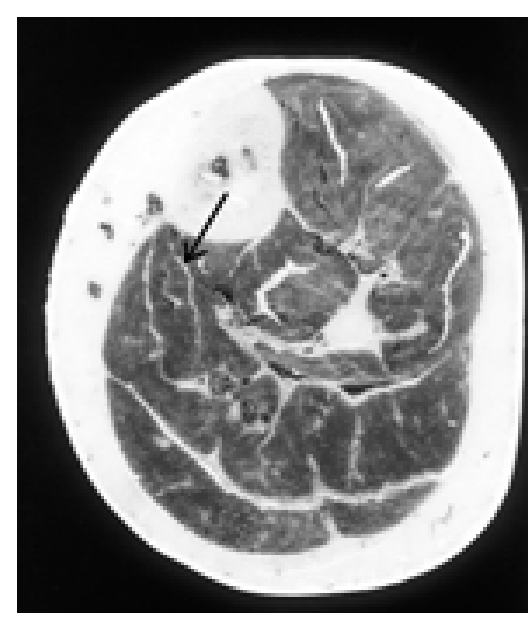

Fig. 5 Cross section of the proximal leg. Venous corrosion cast shows a paratibial perforating vein (arrow). (With permission of the Mayo Clinic and Foundation.) 


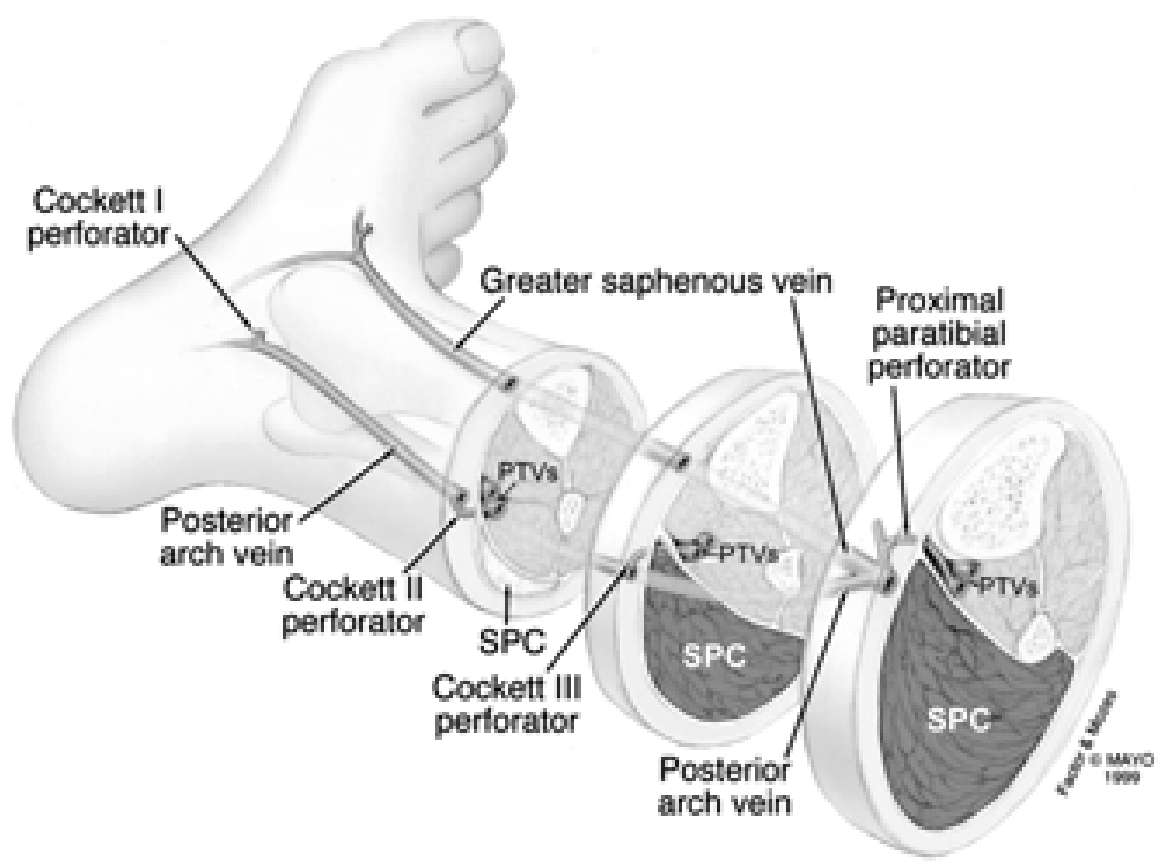

Fig. 6 Relation of the medial direct perforating veins to the deep and superficial (SPC) posterior fascial compartments (PTVs, posterior tibial veins). (With permission of the Mayo Clinic and Foundation.)

(Cockett II, lower Cockett III, and most of the proximal paratibial perforators) an additional incision on the fascia between the deep and superficial posterior compartments is required. Cockett I perforator is usually not available for this endoscopic technique.

On the posterolateral side of the calf direct, peroneal perforators connect the lesser saphenous to the peroneal veins. There are several indirect perforators between the lesser saphenous system and the gastrocnemius and soleus muscles (Fig. 2).

Direct anterior calf perforators connect the anterior tributary of the greater saphenous vein to the anterior tibial veins. The "premalleolar" and the "midcrural" perforators are two constant ones in this region.

Direct perforating veins in the thigh are less numerous than those of the calf. Two major groups on the medial side are the Dodd's and the Hunterian perforators, which both drain the greater saphenous system to the popliteal and superficial femoral veins. Other direct perforators connect the lateral and medial accessory saphenous system and the vein of Giacomini to the profunda femoris vein. 
A
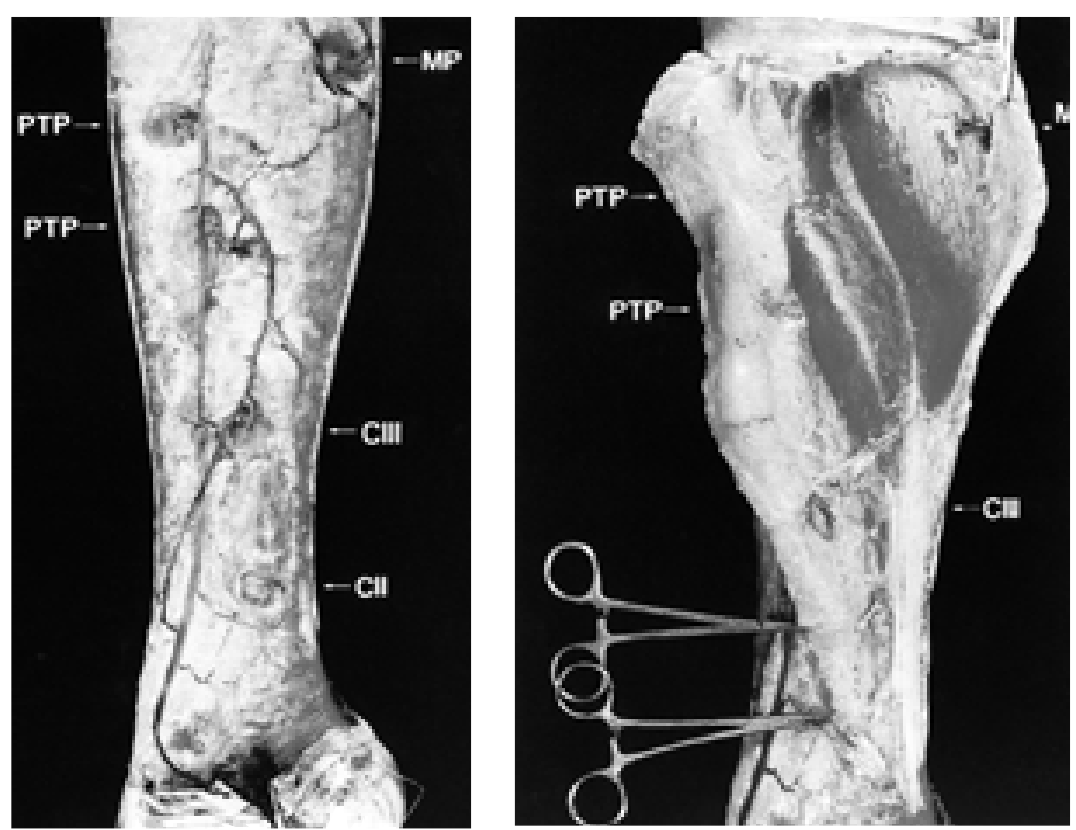

B

Fig. 7 Medial aspect of venous corrosion cast of the left leg. (A) Skin and some of the subcutaneous fat have been removed. The lowest perforating vein correspons to Cockett II and Cockett III drains the posterior arch vein. There are two paratibial perforators: one of those takes its origin from the tributaries of the posterior arch vein and the other, higher one comes directly from the greater saphenous vein. (B) Fascia and subcutaneous fat has been rolled to expose the superficial posterior compartment. The Cockett II and the higher paratibial perforators are not directly accessible from this compartment. MP, Muscle perforator; PTP, paratibial perforator; CII, Cockett; CIII, Cockett III. (With permission of the Mayo Clinic and Foundation.)

\section{REFERENCES}

1. Patten's Foundations of Embryology, 5th ed. Carlson BM, ed. 5th ed. New York: McGraw-Hill; 1988

2. Terminologia Anatomica, International Anatomical Terminology, Federative Committee on Anatomical Terminology. New York: Thieme Medical Publishers; 1998

3. Moneta GL, Nehler MR. The lower extremity venous system: anatomy and physiology of normal venous function and chronic venous insufficiency. In: Gloviczki P, Yao JST, eds. Handbook of Venous Disorders. Guidelines of the American Venous Forum. London: Chapman \& Hall; 1996:3-26

4. Hollinshead WH ed. Anatomy for Surgeons: The Back and Limbs, Vol 3. New York: Harper \& Row; 1969:617-631, 754-758, 803-807

5. Dodd H, Cockett FB. Surgical anatomy of the veins of the lower limb. In: Dodd H, Cockett FB, eds. The Pathology and Surgery of the Veins of the Lower Limb. London: E. \& S. Livingstone; 1956:28-64 
6. Tibbs DJ. Varicose Veins and Related Disorders. Oxford: Butterworths-Heinemann; 1992:204-232

7. Negus D. The blood vessels of lower limb: applied anatomy. In: Negus D, ed. Leg Ulcers: A Practical Approach to Management, 2nd ed. London: Butterworths-Heinemann; 1995:14-29

8. Bergan JJ. Surgical management of primary and recurrent varicose veins. In: Gloviczki P, Yao JST, eds. Handbook of Venous Disorders. Guidelines of the American Venous Forum. London: Chapman \& Hall; 1996:394-415

9. Linton RR. The communicating veins of the lower leg and the operative technic for their ligation. Ann Surg 1938;107:582-593

10. Stolic E. Terminology, division and systematic anatomy of the communicating veins of the lower limb. In: May R, Partsch H, Staubesand J, eds. Perforating Veins. Baltimore: Urban \& Schwarzenberg; 1981:19-34

11. May R. Nomenclature of the surgically most important conncecting veins. In: May R, Partsch H, Staubesand J, eds. Perforating Veins. Baltimore: Urban \& Schwarzenberg, 1981:13-18

12. Kuster G, Lofgren EP, Hollinshead WH. Anatomy of the veins of the foot. Surg Gynecol Obstet 1968;127:817-823

13. Le Dentu A. Anatomic research and physiologic considerations of the venous circulation of the foot and leg (in French). Thése Agrégat, Paris: 1867

14. Sherman RS. Varicose veins: Anatomic findings and an operative procedure based upon them. Ann Surg 1944;120:772-784

15. Sherman RS. Varicose veins: Further findings based on anatomic and surgical dissections. Ann Surg 1949;130:218-232

16. Cockett FB, Jones DEE. The ankle blow-out syndrome: A new approach to the varicose ulcer problem. Lancet 1953;1:17-23

17. Cockett FB. The pathology and treatment of venous ulcers of the leg. Br J Surg $1956 ; 44: 260-278$

18. O'Donnell TF, Burnand KG, Clemenson G, Thomas ML, Browse NL. Doppler examination vs clinical and phlebographic detection of the location of incompetent perforating veins. Arch Surg 1977;112:31-35

19. Fischer R, Fullemann HJ, Alder W. About a phlebological dogma of the localization of the Cockett perforators (in French). Phlébologie 1992;45:207-212

20. Mozes G, Gloviczki P, Menawat SS, Fisher DR, Carmichael SW, Kadar A. Surgical anatomy for endoscopic subfascial division of perforating veins. 1996; J Vasc Surg 24:800-808

21. Boyd AM. Discussion on primary treatment of varicose veins. Proc Royal Soc Med 1948;XLI:633-639

22. Gloviczki P, Cambria RA, Rhee RY, Canton LG, McKusick MA. Surgical technics and preliminary results of endoscopic subfascial division of perforating veins. J Vasc Surg 1996;23:517-523

23. Gloviczki P, Canton LG, Cambria RA, Rhee RY. Subfascial endoscopic perforator vein surgery with gas insufflation. In: Gloviczki P, Bergan JJ, eds. Atlas of Endoscopic Perforator Vein Surgery. London: Springer-Verlag; 1998:125-138

24. Mozes G, Gloviczki P, Kadar A, Carmichael SW. Surgical anatomy of perforating veins. In: Gloviczki P, Bergan JJ, eds. Atlas of Endoscopic Perforator Vein Surgery. London: Springer-Verlag; 1998:17-28 